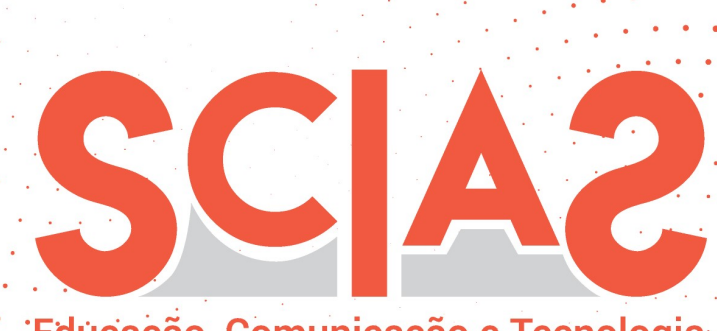

'Edưçaçã̃o, Comunicação e Tecnologia

Atribuiçãa BB CY 4.0

\title{
CAMINHOS DO FEMININO E DO MASCULINO: isolamento social e novas tecnologias
}

Elane Nardotto Rios ${ }^{1}$

Recebido em: 26/06/2020

Aprovado em: 22/12/2020

Mulher, mãe, professora, pesquisadora, feminista fortalecida pelo sagrado feminino, terapeuta reikiana... Quantas mulheres habitam em mim? Quantas mulheres habitam em nós? Inicio este texto com a fala de uma colega de trabalho, do Instituto Federal da Bahia, locus de nossa atuação profissional. Depois de 30 dias de suspensão de atividades docentes, em decorrência da pandemia de Covid-19, o diretor geral marcou uma reunião virtual com xs servidorxs para $10 h o o$ da manhã, e ela disse: "se fosse uma mulher na gestão geral, não teria marcado nesse horário". Tal afirmação materializa algo que todas nós, mulheres, profissionais da educação, entre outras profissões, estamos vivenciando nas nossas casas. Além das demandas da esfera pública, estamos com as demandas da esfera privada - estou falando do lugar de quem trabalha fora e, normalmente, há uma secretária doméstica para ajudar nas tarefas domésticas que, no meu caso, está em sua casa recebendo seu salário e protegida, dada a pandemia. Recordo-me que enquanto ouvia a reunião, estava fazendo o almoço e cuidando da organização da cozinha e mencionei com xs colegas: "essas reuniões virtuais são ótimas porque posso fazer o almoço ao passo que acompanho as discussões e deliberações da reunião”. Ou seja, neste

1 Professora do Instituto Federal da Bahia, feminista fortalecida pelo sagrado feminino, doutora em Educação pela Universidade Federal da Bahia.

E-mail: elanenardoto@yahoo.com.br 
isolamento, é indiscutível como as novas tecnologias sedimentadas na esfera digital possibilitam que, nós, mulheres, possamos estar conectadas com o mundo do trabalho público e privado, garantindo uma aproximação entre o maternar-trabalhar-cuidar-pesquisar-produzir ciência, tudo ao mesmo tempo e na mesma medida, conforme o relato acima. Arrisco a dizer que esse contexto aproximou-me mais das minhas duas filhas e das atividades domésticas haja vista todas as tarefas passaram a ser efetivadas num mesmo espaço-tempo, embora gere um cansaço que, longe de ser do momento atual, é algo que acompanha a condição do ser mulher há algumas décadas.

No livro de minha autoria, "Manuscritos Feministas-Femininos", em vias de publicação, num dos textos, defendo a forma com as sufragistas lutaram e enfrentaram os homens de seu tempo, negando seus úteros e toda feminilidade, sendo necessário, naquele contexto de início de século $\mathrm{XX}$, despertar suas manifestações masculinas a fim de igualar-se aos homens na esfera política e, por consequência, na esfera do mundo do trabalho público. Desde aquele momento, as mulheres vêm conquistando seu espaço em um lugar legitimado e reservado, culturalmente e historicamente, para os homens, sem uma necessidade de eles ressignificarem suas masculinidades, suas formas de dominação e construção de existências, afinal, o mundo foi criado pelos homens que, "gentilmente", cederam um espaço, sob vigilância, para que as mulheres pudessem habitar. No século XXI, as coisas se transmutaram um pouco, mas a presença das mulheres ao lado deles no mundo do trabalho público não está sendo garantia para o despertar do feminino nos homens do mesmo modo que as mulheres necessitaram e necessitam despertar o masculino para atender a lógica patriarcal quando conquistaram e conquistam, diariamente, a autonomia financeira. Desse modo, o mundo público pertence às masculinidades e quem quiser fazer parte da ópera patriarcal, precisa se adequar de modo a negar-se a si, a exemplo das referidas sufragistas que abriram mão de suas vidas privadas e de sua construção feminina para colocar-se ao lado dos homens e sentir-se iguais já que, naquele tempo, as mulheres que encamparam o movimento pelo voto feminino perdiam a guarda dxs filhxs. Se não fosse assim, não estaríamos votando nem tampouco estaríamos ocupando cadeiras no legislativo e elaborando leis para, inclusive, proteger e garantir que as mulheres tenham 
mais espaços na esfera pública. Quando olho para trás, agradeço a essas mulheres que nos antecederam e nos mostraram bravamente que nada "cai do céu” e até lá temos um homem-Deus, fruto do patriarcado. Para onde olhamos, há um Senhor, na terra e no céu.

Sobre o dado de sentirem-se iguais, trago duas questões que se relacionam com o que anunciei acerca do cansaço que nós, mulheres, estamos submetidas: a primeira refere-se ao dado da importância de estarmos na esfera pública e, assim, termos a possibilidade de elaborarmos outras formas de construção do mundo embora isso tudo gere um cansaço, pois precisamos "provar" a todo o tempo que somos capazes para realizar nossos ofícios, muitos deles, inclusive, reservados, historicamente, para os homens. Mesmo que a passos curtos, conseguimos deixar nossas marcas, mostrar as nossas demandas, nossos olhares e conquistar uma autonomia financeira, pessoal e afetiva; uma boa parte é dona dos seus salários e, por isso, donas dos seus processos reprodutivos bem como dos seus corpos, embora há muito a ser feito, levando em conta, sobretudo, as violências a que somos acometidas diariamente. A outra questão imbrica-se à primeira e diz respeito ao dado de que nossa autonomia implicou e implica uma força hercúlea para dar conta das esferas pública e privada, já que, conforme dito, nunca foi necessário que os homens fizessem mudanças nem que despertassem o seu feminino, pois o mundo foi construído por eles e com uma lógica a partir das masculinidades. Ao contrário das mulheres que, para adentrar nesse mundo, precisaram despir-se, não totalmente, de todas as marcas de sua dimensão feminina e privada para adequar-se ao mundo masculino. Embora a luta das mulheres sempre tenha sido pela igualdade, parece-me que a ascensão na esfera pública se presentificou de forma desigual haja vista que para os homens lutar por um espaço nunca foi problema, afinal, o espaço sempre foi seu. Dito de outro modo, nunca foi necessário que os homens adentrassem na esfera privada porque esse lugar sempre pertenceu as mulheres, com exceção daqueles que dividem as atribuições com suas companheiras no espaço doméstico. Oliveira (1999), assim se posiciona:

As mulheres tentaram a passagem da fronteira do mundo dos homens, arrastando, escondidas, as raízes plantadas em casa. Adotaram estilos de vida masculinos sem que os homens se feminizassem. Assim ficaram entre dois mundos, compatibilizando estilos de vida e modos de 
comunicação diferentes, recebendo da sociedade uma ordem esquizofrenizante: seja homem e seja mulher. E foi assim que o sonho de igualdade tropeçou no impossível. Porque a um homem se pede que seja única e exclusivamente homem, aquele que representa a regra e o padrão face ao qual a mulher deve ser ao mesmo tempo igual e diferente (OLIVEIRA, 1999, p. 13).

Como podemos verificar, independente do contexto atual e levando em conta se temos ou não uma profissional para nos ajudar nos trabalhos da esfera privada, considero que essa questão vai além desse isolamento social com as respectivas atividades suspensas.Nesse cenário uma pergunta se presentifica: nós, mulheres, estamos partilhando as atividades domésticas com nossxs companheirxs, de modo a garantir, com tranquilidade, o trabalho remoto, através das novas tecnologias, com nossas atividades profissionais e de pesquisa? Nos caminhos do feminino e do masculino, o mundo domésticoprivado esteve a cargo das mulheres, e sempre tivemos e temos uma relação desigual no que concerne a essa partilha de tarefas em casa. Parece-me que essa dificuldade pode estar se materializando neste isolamento considerando a reportagem" "Produtividade de mulheres pesquisadoras é mais afetava pela pandemia" em que mostra um levantamento, no Brasil, mediante o projeto Parent in Science, de que, apenas, $13 \%$ das mulheres-mães de pós-graduação que responderam ao questionário, estão conseguindo trabalhar na produção acadêmica levando em conta que as atividades escolares dxs filhxs estão sendo efetivadas em casa ou no caso das escolas públicas, as atividades estão suspensas.

Como pesquisadora e escritora, encontro-me numa situação mais confortável porque minhas filhas têm uma autonomia pela idade que possuem e gerenciam as atividades escolares. Talvez, por isso, pude participar de 5 lives, orientar xs estudantes da Pós-Graduação "Formação Docente e Práticas Pedagógicas" que coordeno no Instituto Federal da Bahia, além de escrever o livro "Filosofias Feministas...da vida experimentada". Tudo isso com o apoio das novas tecnologias e dividido com "as paradinhas" para varrer a casa, fazer almoço, lavar roupas ou colocar na máquina de lavar, entre outras tarefas domésticas.

${ }^{2}$ https://ufmg.br/comunicacao/noticias/produtividade-de-pesquisadoras-mulheres-emais-afetada-pela-pandemia 
No entanto, para quem tem filhos menores, a situação se configura de outra forma, a exemplo da prefaciadora do livro citado "Filosofias Femininas...", mulher, pesquisadora, mãe de dois filhos menores e um deles com autismo. Ao entregar o prefácio, disse-me que leu o livro, sempre depois das 23h, horário em que a casa está silenciosa e, assim, pode desfrutar de uma leitura mais atenta. Essa mesma mulher prefaciadora, intelectual e professora, é a mesma que acorda cedo para acompanhar os filhos nas atividades remotas escolares bem como dá conta das tarefas domésticas.

Sem a escola, sem as secretárias domésticas que precisam estar protegidas em suas casas e sem o apoio dxs companheirxs - realidade de muitas -, considero que esse isolamento está materializando uma sobrecarga para muitas mulheres - no nosso relato, limitei-me a versar sobre as professoras - que necessitam dar conta do trabalho remoto e do trabalho "presencial" em suas casas. No meu campo empírico, percebo que as mulheres vêm compartilhando "memes", piadas, recados para os homens e desabafos nos grupos de whatsapp que participo, o que revela como estão se sentindo nesse momento. Conforme mencionei, sem sombra de dúvida que as novas tecnologias é uma aliada não só para garantir o trabalho remoto, como também para que nós possamos acessar aplicativos de meditação, treinos de academia, yoga, lives de artistas, entre outras para, assim, trazer leveza, diversão e saúde emocional e mental diante do cenário delineado, seja no mundo com a materialidade de um vírus que está se expandindo e com um grau elevado de letalidade, seja em casa com todas as demandas. Uma oportunidade de reflexão sobre os caminhos do feminino e do masculino para ressignificarmos as nossas lutas e proclamarmos uma verdadeira igualdade entre homens e mulheres para que possamos, vivenciar nosso masculino e feminino nas nossas diferenças, inteirezas e com vistas a uma parceria. A travessia é árdua para muitas e esse pode ser o momento de balizar, também, se estamos envolvidas em relações abusivas em que não ocorre um companheirismo e partilha de responsabilidades.

Por fim, conquistamos muito, ao longo dos séculos, mas chegou a hora de considerar se queremos carregar o mito da Mulher Maravilha em uma sociedade 
que se acomodou a nos olhar, de acordo com Oliveira (1999), como bissexuais de nós mesmas ou gêmeas dos homens.

\section{Referência}

OLIVEIRA, Rosiska Darcy de. Elogio da diferença - o feminino emergente. São Paulo: Brasiliense, 1999. 